\title{
Target Strength for Fish Identification Using Echo Sounder
}

\author{
Sunardi (Corresponding author) \\ Electrical Engineering Department, Universitas Ahmad Dahlan \\ Jl. Prof. Soepomo, Umbulharjo 55164, Yogyakarta, Indonesia \\ Tel: 62-274-379-418Ｅ-mail: sunargm@ee.uad.ac.id \\ Jafri Din \\ Electrical Engineering Faculty, Universiti Teknologi Malaysia \\ Skudai 81310, Johor Bahru, Malaysia \\ E-mail: jafri@fke.utm.my
}

Anton Yudhana

Electrical Engineering Department, Universitas Ahmad Dahlan

Jl. Prof. Soepomo, Umbulharjo 55164, Yogyakarta, Indonesia

E-mail: eyudhana@uad.ac.id

Raja Bidin Raja Hassan

Marine Fishery Resources Development and Management Department

Kuala Terengganu 21080, Terengganu, Malaysia

E-mail: rbidin@seafdec.org

The work is supported by the Vote \# 79011 managed by UTM Research Management Center (RMC)

\begin{abstract}
Identification of target strength (TS) of fish species in the South China Sea has been conducted using Furuno FQ- 80 (38/120 kHz echo sounder). This study introduces new experimental method which is combination of in situ and ex situ experiment by applying net cage at undersea. This research involved Selar boops (Oxeye scad) and Megalaspis cordyla (Torpedo scad) in separate net cage at the bottom of the vessel. TS, depth, and position (x-y-z) of fish have been monitored at every ping using echogram. TS of Selar boobs at low and high frequency are $-44.49 \mathrm{~dB}$ for source level $(\mathrm{SL})$ of $236 \mathrm{~dB}$ and $-43.96 \mathrm{~dB}$ for SL of $228 \mathrm{~dB}$. For Megalaspis cordyla, TS are $-45.34 \mathrm{~dB}(\mathrm{SL}=230 \mathrm{~dB})$ and -43.06 $\mathrm{dB}(\mathrm{SL}=225 \mathrm{~dB})$ for low and high frequency respectively. The results show that Megalaspis cordyla produce higher TS whereas the position is deeper and smaller size than Selar boops at low and high frequency.
\end{abstract}

Keywords: Echo sounder, Target strength, FQ-80, Fish identification, Selar boops, Megalaspis cordyla

\section{Introduction}

The ocean is a complex environment with various hidden physical phenomena. One of them is fisheries resources that challenge people to explore. It leads the scientist to establish fisheries acoustic science to study fisheries resources more. Fisheries acoustic then become a particular field hydro acoustic that has significant role on undersea research. As inheritance of hydro acoustic, fisheries acoustic has also two major divisions: active and passive one. Refer to Horne (2000) active acoustic includes subjects such as echo sounder and sonar, where pulses of sound are transmitted into the water and reflect off objects such as fish, submarines, or seabed.

The science of underwater acoustics was given its major impetus by the sinking of Titanic in 1912. This event leaded to the invention of ultrasonic echo ranging devices for iceberg detection. Using the devices with $1100 \mathrm{~Hz}$ frequency for 
projector and receiver, the first underwater echo was received from an iceberg at a range of about 2 miles in 1914. Then, it brought underwater acoustic as the important tools for submarine detection.

Underwater acoustic then had been utilized to detect the fish abundance. The use of echo for fish detection was pioneered by Balls in 1933. Size and reflectivity of sound by the fish are combined into a parameter called the backscattering cross section $\left(\sigma_{b s}\right)$, which is essentially the acoustic size of the object. The backscattering cross section can be expressed as the amount of reflected sound intensity measured one meter away from the target, relative to the amount of energy incident upon the target, as shown in Figure 1. This parameter usually expressed in logarithmic then called the target strength (TS) and expressed in dB (Hydroacoustic, 1989).

Acoustic backscattering by fish depends on fish size, anatomical characteristics, morphology of the body, morphology and composition of swim bladder, location of fish in the acoustic beam, fish behavior and frequency of transducer (Horne, 1998) (Jech, 2002) (Sawada, 2002) (Hazen, 2003). Horne (2003) also identified that the ratio of acoustic wavelength to fish length had influence to acoustic backscattering. Moreover, Horne (2000) divide the factors affecting acoustic backscattering into physical factors such associated with the transmission of sound through a compressible fluid, and the biological factors associated with the location, reflective properties, and behavior of the target. Furthermore, Foote (1990a) and Ona (1990) defined that the biological factors composed of behavioral, morphological, ontogenetic, and physiological factors. The definition of ontogeny is restricted to the development and growth of the fish body and swim bladder. Physiology is restricted to fish feeding and gonad development through the reproductive cycle. Behavior includes the tilt and roll of individual organisms as well as the aggregation and polarized movement (i.e. schooling) by fish groups.

The swim bladder which is an oval-shaped sac found in the fish's abdominal cavity is considered to be responsible for most of the fish's acoustic backscattering energy (Foote, 1990b) and consequently to its TS. Moreover, Horne (1998) identified that acoustic scattering by a swim bladder is four or more times greater than it by fish bodies at any given frequency. At different time, swim bladder can be filled with varying amounts and compositions of gases (same as atmospheric gases; carbon dioxide, oxygen, and nitrogen). The bladder has developed as an extension of the gut wall (Mukai, 1996) (Martin, 2000). Swim bladder varies naturally in volume and shape. It possibly causes the fish TS. The important factors that are assumed to alter the TS significantly are stomach content, gonads, body-fat content, pressure, and tilt angle (Jorgensen, 2003).

The measurement of TS can be conducted both in situ and ex situ. In situ TS measurements for fish detection (Figure 2) incorporate ping-to-ping variability from ensonified organisms but do not permit independent measurement or the manipulation of sources that influence TS. Ex situ one is to measure TS for specific fish with known length in which tilt and depth are controlled.

Kloser (2003), Zhao (2006), Pena (2008) are among others who study of in situ measurement method in the sea using echo sounder for Orange roughly (Hoplostethus atlanticus) from Australia-New Zeland-Namibia, Young hairtail (Trichiurus haumela), and Chilean jack mackerel (Trachurus symmetricus murphyi) respectively. In other side, Abe (2004), Sawada (2004), and Kang (2004) are study of ex situ measurement in the laboratory for Juvenile Walleye pollock (Theragra chalcogramma), Japanese common squid (Todarodes pacificus), and Bluegill (lepomis macrochirus).

The previous literatures show the application of acoustic to study fisheries resources for various fish species. However, the fish involved are very specific associated to its habitat. This research tries to study TS for Selar boops (Oxeye scad) and Megalaspis cordyla (Torpedo scad) that are the most famous and in demand fish in Malaysia. This research also introduces new experimental method which is combination of in situ and ex situ experiment by applying net cage at undersea.

\section{Materials and method}

The location of this research was the South China Sea, north of Redang Island, Terengganu, Malaysia as shown in Figure 3. Two species: Selar boops (Oxeye scad) and Megalaspis cordyla (Torpedo scad) were involved (Figure 4). The detail characteristics of Selar boops and Megalaspis cordyla are listed in Table 1.

This research combined in situ and ex situ methods. The net cage size of $3 \mathrm{~m} \times 3 \mathrm{~m} \times 3 \mathrm{~m}$ was placed at the bottom of the vessel (Figure 5) after calibration set up. The TS measurement of the cage with and without fish has been conducted. Furuno FQ-80 Scientific Echo Sounder was utilized to collect data. FQ-80 is included in the research vessel of KK Senangin II, with dual-frequency capabilities, low-frequency $(38 \mathrm{kHz})$ and high-frequency $(120 \mathrm{kHz})$.TS value, depth, and position of targeted fish can be viewed at every ping by recorded echogram using FQ-80 Analyzer.

TS value, depth, and position (x-y-z) of single fish which detected at every ping at low or high frequency has been observed from Top View of TS as shown in Figure 6. This display shows the direction and depth of single fish. The $\mathrm{x}$-axis is starboard $(+\mathrm{x})$ and port $(-\mathrm{x})$, the $\mathrm{y}$-axis is bow $(+\mathrm{y})$ and stern $(-\mathrm{y})$. Depth recorded is the distance between fish and transducer. The $\mathrm{z}$-axis is angle between fish and center of axis which measured from transducer. 
The transducer is positioned at the bottom of vessel and $2.8 \mathrm{~m}$ from water surface. FQ- 80 must be properly calibrated in order to measure biomass effectively. The calibration is performed using a "calibration sphere," a sphere which has a precise TS value. Calibration allows the determination of backscattering strength or target strength of individual fish. The age of the transducer does not affect the calibration. However, we have to be careful of transducer cleanliness and its damage condition. Since, they affect measurement precision. For this reason, any marine growth, barnacles, and oysters had to be removed from the transducer before performing the calibration. Calibration sphere was $38.1 \mathrm{~mm}$ diameter and bind to the net with nylon string. Deep sea multifilament \#20 was used to the fishing line for the reel. The monofilament \#10 - \#15 was used to bind the calibration sphere. The underwater setup for calibration and calibration ball are shown in Figure 5.

Processor and Analyzer Units were always on-line and displayed the same echo sounder picture (echogram) on the low or high frequency. While watching the Top View of TS display, the position of calibration sphere was adjusted so that the "red ball" on the scope comes to the center of $x-y$ axis. The measured TS should be maintained in the range of \pm 2 $\mathrm{dB}$ from calibration sphere TS or standard TS, i.e. is $-42.30 \mathrm{~dB}$ and $-40.10 \mathrm{~dB}$ for low and high frequency. The detail of TS standard for any frequency and calibration sphere as shown as are listed in Table 2.

\section{Results and discussions}

This section discusses implementation of echo sounder on TS measurement's results included the calibration process and net measurement with or without fish. Table 3 list the parameters used in the calibration process. The calibration ball appearance has been observed and can be viewed from echogram.

The position of calibration ball was varied from 11.36 to $11.61 \mathrm{~m}$ depth from transducer, whereas the transducer was $2.8 \mathrm{~m}$ from the water surface. This different depth of calibration ball has been influenced by sea wave in underwater. The echogram of the calibration ball appearance has been observed and can be viewed in the Figure 7a.

Total pings of echogram are 119 pings. Single fish TS detected are $-46.49 \mathrm{~dB}$ of 97 pings for low frequency and -45.62 $\mathrm{dB}$ of 113 pings for high frequency. Unit conversion from TS $(\mathrm{dB})$ to backscattering cross section must be conducted because the data on $\mathrm{dB}$ unit can not to be average directly. The new Source Level (SL) must be changed as considered in the Table 4.

Position of the upper net and lower net from the transducer are $2.3 \mathrm{~m}$ and $5.3 \mathrm{~m}$ (or $5.1 \mathrm{~m}$ to $8.1 \mathrm{~m}$ from water surface). Total of 79 Selar boops has been put in the net cage 12 hours before TS measurement for adaptation to avoid fish unstable condition. Of 79 fish, only 44 survived and were utilized in this study. The average and range of fork length were $209.59 \mathrm{~mm}$ and $175-233 \mathrm{~mm}$ while the average and range of weight were 165.00 gram and 100-250 gram.

Selar boobs had been detected at 6.98 to 7.69 meters of depth. The echogram of the fish appearance in the net cage is shown in Figure 7b. Fish appearance at low frequency is more than at high frequency because of beam width differences.

For $236 \mathrm{~dB}$ SL, fish TS detected at low frequency has a range of -47.40 to $-38.33 \mathrm{~dB}$. Its average is $-44.49 \mathrm{~dB}$. Otherwise, TS at high frequency varies from -45.19 to $-42.76 \mathrm{~dB}$ for $228 \mathrm{~dB}$ of SL. Its average is $-43.96 \mathrm{~dB}$. It shows that TS of Selar boops at higher frequency is stronger $(0.53 \mathrm{~dB})$ than it of lower frequency. If the $8 \mathrm{~dB}$ differences between SL at high frequency and low frequency is considered then this difference becomes more significant. TS data sample of Selar boops TS recorded are displayed in Table 5.

Total of 9 Megalaspis cordyla were used in this study. They have fork length of 133-155 mm with 144 mm of average. The average of weight is 30 gram which the range is 15-40 gram. This size is smaller than selar boops. Megalaspis cordyla were detected at 8.44 to 10.99 meters of depth. This position is deeper than Selar boops.

The average of TS at low and high frequency for Megalaspis cordyla are $-45.34 \mathrm{~dB}(\mathrm{SL}=230 \mathrm{~dB})$ and $-43.06 \mathrm{~dB}(\mathrm{SL}=$ $225 \mathrm{~dB})$. It shows that TS of Megalaspis cordyla at higher frequency is stronger $(2.28 \mathrm{~dB})$ than it at lower frequency. If the $5 \mathrm{~dB}$ differences between SL at high frequency and low frequency is considered then this difference will be more significant.

These results of TS have no significantly differences for both fish, but Megalaspis cordyla need less of SL. It shows that Megalaspis cordyla produce higher TS whereas the position is deeper and smaller size than Selar boops at low and high frequency. The details data of this comparison can be shown in Table 6.

\section{Conclusion}

TS for fish identification of Selar boops and Megalaspis cordyla at the bottom of the vessel using FQ-80 echo sounder have been conducted. TS value, depth, and position (x-y-z) of fish targeted can be monitored from echogram using FQ-80 Analyzer. Megalaspis cordyla produce higher TS whereas the position is deeper and smaller size than Selar boops at low and high frequency. 


\section{References}

(1989). Hydroacoustics Manual. Biosonic, Inc. USA, pp: 1-15.

(2004). Fishbase: a Global Information System on Fishes. World Fish Center. [Online] Available: http://www.fishbase.org

(2004). Furuno FQ-80 Scientific Echo Sounder, Furuno Electric, Co. Ltd. Nishinomiya, Japan.

Abe, K., Sadayasu, K., Sawada, K., Ishii, K., and Takao, Y. (2004). Precise target strength measurement and morphological observation of juvenile walleye pollock (Theragra chalcogramma). OCEAN'04.MTTS/IEEE TECHNO-OCEAN'04, Japan, Vol. 1, pp. 370-374.

Foote, K.G. (1990a). Averaging of Fish Target-Strength Functions. Journal of the Acoustical Society of America, 67: 504-515.

Foote, K.G. (1990b). Importance of the Swimbladder in Acoustic Scattering by Fish: a Comparison of Gadoid and Mackerel Target Strengths. Journal of the Acoustical Society of America, 67: 2084-2089.

Gauthier, S. and Horne, J.K. (2004). Potential Acoustic Discrimination within Boreal Fish Asemblages. ICES Journal of Marine Science, 61: 836-845.

Hazen, E.L. and Horne, J.K. (2003). A method for Evaluating the Effects of Biological Factors on Fish Target Strength. ICES Journal of Marine Science, 60: 555-562.

Horne, J. K. (2000). Acoustic Approaches to Remote Species Identification: a Review. Fisheries Oceanography, 9(4): 356-371.

Horne, J. K. and Clay, C. J. (1998). Sonar Systems and Aquatic Organisms: Matching Equipment and Model Parameters. Can. J. Fish. Aquat. Sci. 55: 1296-1306.

Horne, J.K. (2003). The Influence of Ontogeny, Physiology, and Behavior on Target Strength of Walleye pollock (Theragra chalcogramma). ICES Journal of Marine Science, 60: 1063-1074.

Jech, J. M. and Horne, J. K. (2002). Three-dimensional Visualization of Fish Morphometry and Acoustic Backscatter. ARLO, 3(1): 35-40.

Jorgensen, R. (2003). The Effects of Swimbladder Size, Condition, and Gonads on the Acoustic Target Strength of Mature Capelin. ICES Journal of Marine Science, 60: 1056-1062.

Kang, D., Iida, K., Mukai, T., and Hwang, D. (2004). Acoustic target strength of Japanese common squid, Todarodes pacificus, and important parameter influencing its TS: swimming angle and material properties. OCEAN'04.MTTS/IEEE TECHNO-OCEAN'04, Japan, Vol. 1, pp. 364-369.

Kloser, R.J., and Horne, J.K. (2003). Characterizing uncertainty in target-strength measurements of a deepwater fish: orange roughly (Hoplostethus atlanticus). ICES Journal of Marine Science, 60: 516-523

Martin. (2000). Anphys Courses. [Online] Available: http://www.bio.division.edu

Mukai, T. and Iida, K. (1996). Depth Dependence of Target Strength of Live Kokanee Salmon in Accordance with Boyle's Law. ICES Journal of Marine Science, 53: 245-248.

Ona, E. (1990). Physiological Factors Causing Natural Variations in Acoustic Target Strength of Fish. Journal of the Marine Biological Association of the United Kingdom, 70: 107-127.

Pena, H. (2008). In Situ Target Strength Measurements of Chilean Jack Mackerel (Trachurus symmetricus murphyi) Collected with a Scientific Echosounder Installed on a Fishing Vessel. ICES Journal of Marine Science, 2008: 594-604.

Sawada, K., Mukai, T., and Sadayasu, K. (2004). Estimation of the Variation in Target-Strength of Fish under Pressure Condition. OCEAN'04.MTTS/IEEE TECHNO-OCEAN'04, Japan, Vol. 1, pp. 389-400.

Sawada, K., Takao, Y., and Miyanohana, Y. (2002). Introduction of the Precise Target Strength Measurement for Fisheries Acoustics. Turk J Vet Anim Sci. 26: 209-214.

Zhao, X. (2006). In Situ Target Strength Measurement of Young Hairtail (Trichiurus haumela) in the Yellow Sea. ICES Journal of Marine Science, 63: 46-51. 
Table 1. Fish characteristics

\begin{tabular}{|c|c|c|}
\hline & Selar boops & Megalaspis cordyla \\
\hline Family & Carangidae & Carangidae \\
\hline Order & Perciformers & Perciformers \\
\hline Class & Actinopterygii & Actinopterygii (ray-finned fishes) \\
\hline Fish base name & Oxeye scad & Torpedo scad \\
\hline Max. size & $30.0 \mathrm{~cm}$ & $80.0 \mathrm{~cm}$ \\
\hline Environment & Reef-associated; marine; depth: $35-500 \mathrm{~m}$ & $\begin{array}{l}\text { Reef-associated; brackish; marine; depth: } \\
20-100 \mathrm{~m}\end{array}$ \\
\hline Climate & Subtropical; $19^{0} \mathrm{~N}-22^{0} \mathrm{~S}$ & Tropical; $47^{\circ} \mathrm{N}-22^{\circ} \mathrm{S}, 40^{\circ}-156^{\circ} \mathrm{E}$ \\
\hline Importance & $\begin{array}{l}\text { Fisheries: commercial; price category: } \\
\text { medium; price reliability: very questionable: } \\
\text { based on ex-vessel price for species in this } \\
\text { family }\end{array}$ & $\begin{array}{l}\text { Fisheries: highly commercial; price reliability: } \\
\text { high }\end{array}$ \\
\hline Resilience & $\begin{array}{l}\text { High, minimum population doubling time less } \\
\text { than } 15 \text { months }(\mathrm{K}=1.90)\end{array}$ & $\begin{array}{l}\text { Medium, minimum population doubling time } 1.4 \\
-4.4 \text { years }(\mathrm{K}=0.13-0.35)\end{array}$ \\
\hline Distribution & $\begin{array}{l}\text { Pacific Ocean: Andaman islands to Vanuatu, } \\
\text { North to the Philippines, South to Northern } \\
\text { Australia }\end{array}$ & $\begin{array}{l}\text { Indo-West Pacific: East Africa to Japan and } \\
\text { Australia. }\end{array}$ \\
\hline Morphology & $\begin{array}{l}\text { Dorsal spines (total): 9-9; dorsal soft rays } \\
\text { (total): 23-25, anal spines: } 3 \text {, anal soft rays: } \\
\text { 19-21, Color blue-green above, silvery to } \\
\text { silver-gold below. Very large eyes. Usually } \\
\text { shows yellow band. Lower margin of gill } \\
\text { opening with a deep furrow. Operculum with } \\
\text { black spot. Breast fully scaled. } 43-46 \text { large } \\
\text { and strong scutes. First } 2 \text { anal fin spines } \\
\text { detached; pectoral fins falcate. }\end{array}$ & $\begin{array}{l}\text { Dorsal spines (total): } 9 \text { - 9; Dorsal soft rays } \\
\text { (total): } 18 \text { - 20; Anal spines: } 3 \text {; Anal soft rays: } 16 \\
\text { - 17. Color bluish grey to green dorsally; silvery } \\
\text { below; dark fins. Opercula with a large black } \\
\text { spot. 51-59 strong, very large scutes. Anal fin } \\
\text { with } 2 \text { detached spines. Numerous dorsal and } \\
\text { anal finlets are distinct. }\end{array}$ \\
\hline Biology & $\begin{array}{l}\text { Occurs inshore. Forms schools. Feeds on } \\
\text { planktonic and benthic invertebrates. }\end{array}$ & $\begin{array}{l}\text { Primarily oceanic, lives near the surface of } \\
\text { coastal waters. Forms schools and feeds mainly } \\
\text { on fishes. Generally marketed fresh. }\end{array}$ \\
\hline
\end{tabular}

This fish characteristics is published by World Fish Center (2004) and online available at the http://www.fishbase.org.

Table 2. TS standard for calibration

\begin{tabular}{|l|c|c|}
\hline & Frequency $38 \mathrm{kHz}$ & Frequency $120 \mathrm{kHz}$ \\
\hline Radius of calibration sphere & $38.10 \mathrm{~mm}$ & $38.10 \mathrm{~mm}$ \\
\hline TS of calibration sphere & $-42.30 \mathrm{~dB}$ & $-40.10 \mathrm{~dB}$ \\
\hline
\end{tabular}

This standard is available in the Furuno FQ-80 Scientific Echo Sounder (2004). 
Table 3. Parameters for calibration

\begin{tabular}{|l|c|c|}
\hline \multicolumn{1}{|c|}{ Parameters } & Low frequency & High frequency \\
\hline Frequency $(\mathrm{kHz})$ & 38 & 120 \\
\hline Sound speed $(\mathrm{m} / \mathrm{s})$ & 1500 & 1500 \\
\hline SL $(\mathrm{dB})$ & 229.9 & 229.5 \\
\hline ME $(\mathrm{dB})$ & -190 & -190 \\
\hline Gain $(\mathrm{dB})$ & 146.69 & 146.69 \\
\hline Absorption $(\mathrm{dB} / \mathrm{km})$ & 10 & 44 \\
\hline Beam width $(\mathrm{dB})$ & -22.9 & -23.3 \\
\hline Pulse length $(\mathrm{ms})$ & 0.228 & 0.142 \\
\hline TVG line $(\mathrm{dB} / \mathrm{V})$ & 60 & 60 \\
\hline Noise level $(\mathrm{dB})$ & -150 & -150 \\
\hline TD radius $(\mathrm{m})$ & 0.4 & 0.1 \\
\hline TD distance $(\mathrm{m})$ & 0.32 & 0.10 \\
\hline 3dB beam width $($ degree $)$ & 3.1 & 3.1 \\
\hline
\end{tabular}

These parameters must be adjusted in the calibration process in order to appearance of ball and fish is clearly detected and monitored by echogram.

Table 4. Example of calibration results

\begin{tabular}{|l|c|c|}
\hline Parameters & Low frequency $(\mathrm{dB})$ & High frequency $(\mathrm{dB})$ \\
\hline SL & 229.90 & 229.50 \\
\hline TS(f) & -42.30 & -40.10 \\
\hline Measured TS & -46.49 & -45.62 \\
\hline Measured TS - TS(f) & -4.19 & -5.52 \\
\hline New SL & $229.9+(-4.19)=225.71$ & $229.5+(-5.52)=223.08$ \\
\hline
\end{tabular}

The result of calibration process is new Source Level (SL) considered this calculation.

Table 5. Example of various fish detected of Selar boops

\begin{tabular}{|c|c|c|c|c|c|}
\hline & $\begin{array}{c}\text { Depth } \\
(\mathrm{m})\end{array}$ & $\begin{array}{c}\mathrm{x} \\
(\mathrm{deg})\end{array}$ & $\begin{array}{c}\mathrm{y} \\
(\mathrm{deg})\end{array}$ & $\begin{array}{c}\mathrm{z} \\
(\mathrm{deg})\end{array}$ & $\begin{array}{c}\mathrm{TS} \\
(\mathrm{dB})\end{array}$ \\
\hline \multirow{2}{*}{ Low frequency } & 4.86 & 26.20 & -50.10 & -2.09 & -46.64 \\
\cline { 2 - 6 } & 4.82 & 32.70 & -25.30 & -1.05 & -46.60 \\
\hline \multirow{2}{*}{ High frequency } & 4.61 & 48.20 & -55.70 & -2.32 & -43.92 \\
\cline { 2 - 6 } & 4.61 & 23.80 & -18.20 & -0.76 & -45.19 \\
\hline
\end{tabular}

This table shows that TS of Selar boops obtained from low and high frequency. TS recorded of higher frequency is stronger than it at lower frequency whereas depth is no significantly differences. 
Table 6. Comparison of Selar boops and Megalaspis cordyla

\begin{tabular}{|l|c|c|}
\hline Parameters & Selar boops & Megalaspis cordyla \\
\hline Total of sample & 44 & 9 \\
\hline Range of fork length $(\mathrm{mm})$ & $175-233$ & $133-155$ \\
\hline Average of fork length $(\mathrm{mm})$ & 209.59 & 144 \\
\hline Range of weight $(\mathrm{gram})$ & $100-250$ & $15-40$ \\
\hline Average of weight $(\mathrm{gram})$ & 165.00 & 30 \\
\hline Depth from water surface $(\mathrm{m})$ & $6.98-7.69$ & $8.44-10.99$ \\
\hline Average of TS at low frequency $(\mathrm{dB})$ & $-44.49(\mathrm{SL}=236)$ & $-45.34(\mathrm{SL}=230)$ \\
\hline Average of TS at high frequency $(\mathrm{dB})$ & $-43.96(\mathrm{SL}=228)$ & $-43.06(\mathrm{SL}=225)$ \\
\hline
\end{tabular}

This table shows comparison for both fish in this study and its results

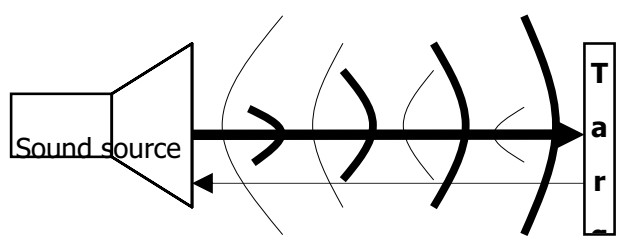

(a) Reflection of sound

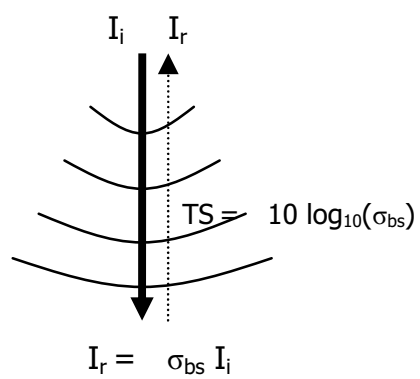

(b) Target strength

Figure 1. Sound reflection and target strength

When the sound wave encounters a density difference (i.e. target), an echo propagates radially outward from the target back to a receiver (a). Size and reflectivity of sound are combined into a parameter called the backscattering cross section $\left(\sigma_{b s}\right)$, which expressed as the amount of reflected sound intensity measured one meter away from the target, relative to the amount of energy incident upon the target. This parameter usually expressed in logarithmic then called the target strength (TS) (b). 


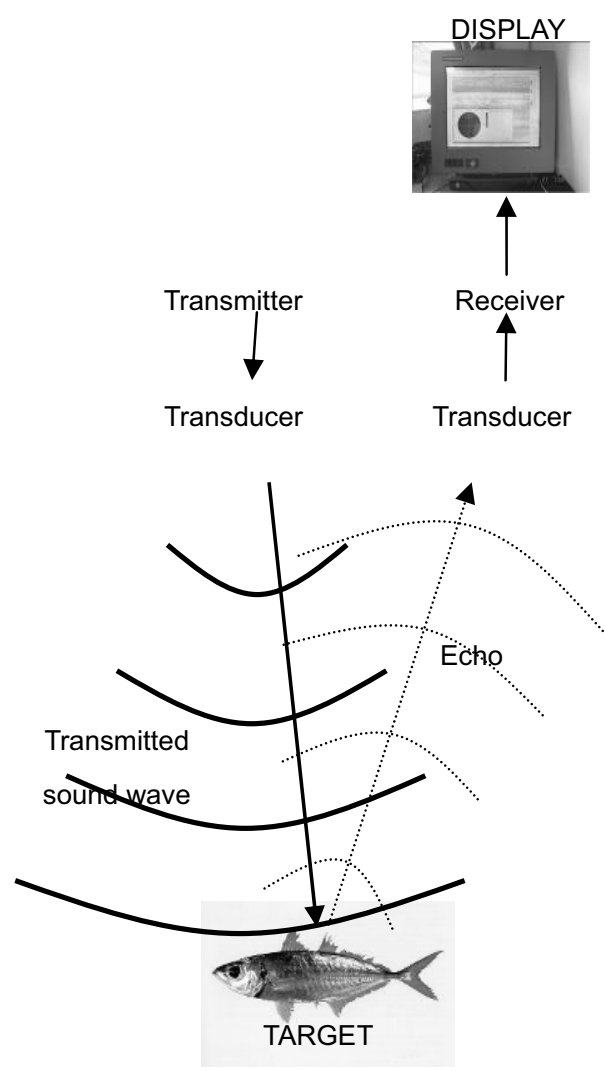

Figure 2. Fish detection using echo sounder

Transmitter of an echo sounder sends out a beam of sound through a transducer. Sound then reflected off objects and the echoes are detected back at transducer and displayed.

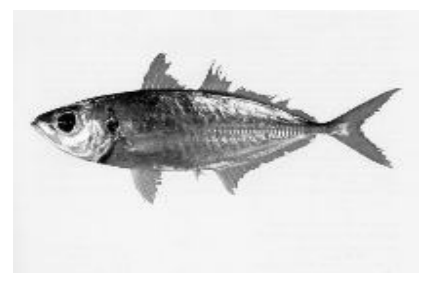

(a) Selar boops

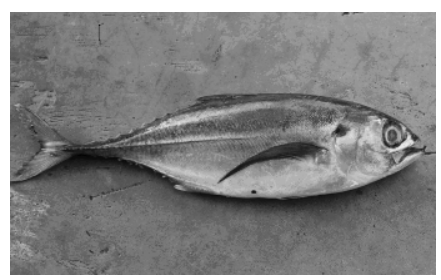

(b) Megalaspis cordyla

Figure 3. Fish studied

This figure captures two of most famous and in demand fish species in Malaysia Selar boops (a) and Megalaspis cordyla (b) 


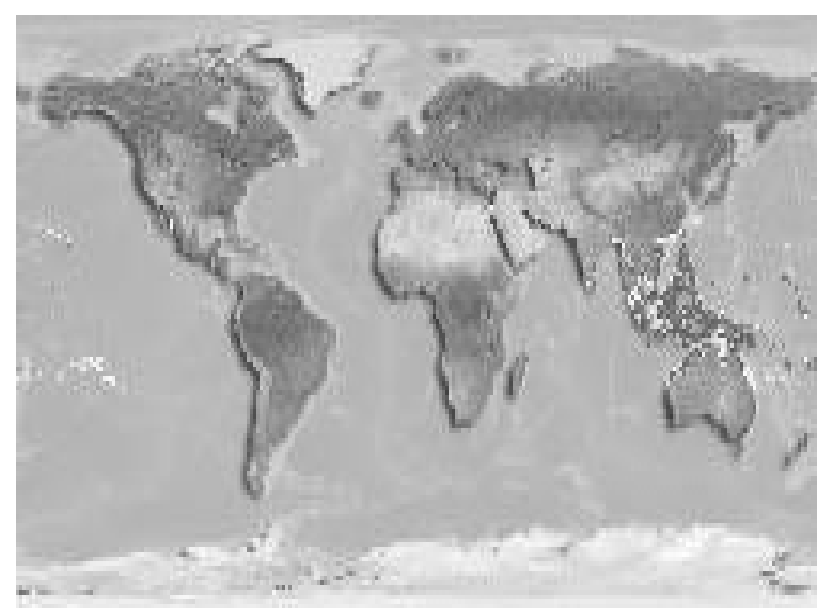

(a) Distribution of fish studied in the world

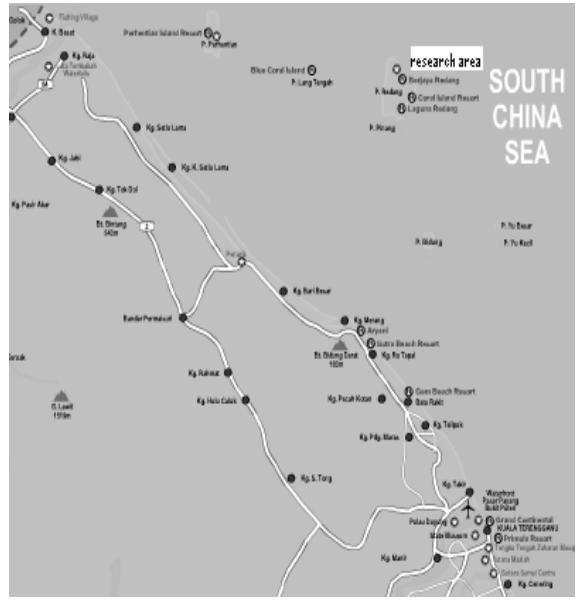

(b) Research location in Malaysia

Figure 4. Fish distribution and research location

World map of distribution of Selar boops and Megalaspis cordyla in the Pacific Ocean: Andaman islands to Vanuatu, North to the Philippines, South to Northern Australia and Indo-West Pacific: East Africa to Japan and Australia (a). Location of research is near of Redang Island, Terengganu, Malaysia (b).

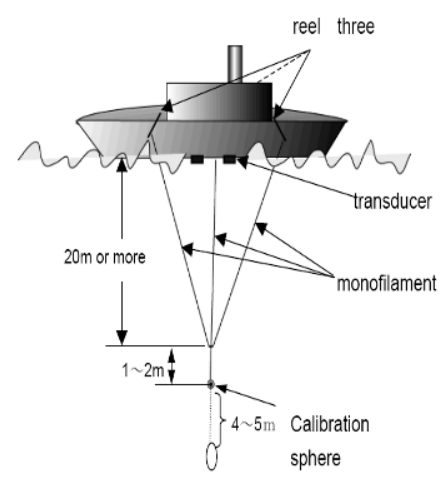

(a) Calibration setup

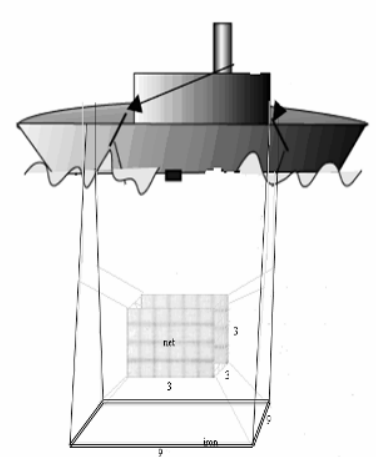

(b) Net cage setup

Figure 5. Setup for Calibration and net cage underwater

The transducer is positioned at the bottom of vessel and $2.8 \mathrm{~m}$ from water surface. FQ- 80 must be properly calibrated using a "calibration sphere" (a). The net cage size of $3 \mathrm{~m} \times 3 \mathrm{~m} \times 3 \mathrm{~m}$ was placed at the bottom of the vessel for fish habitat (b). 


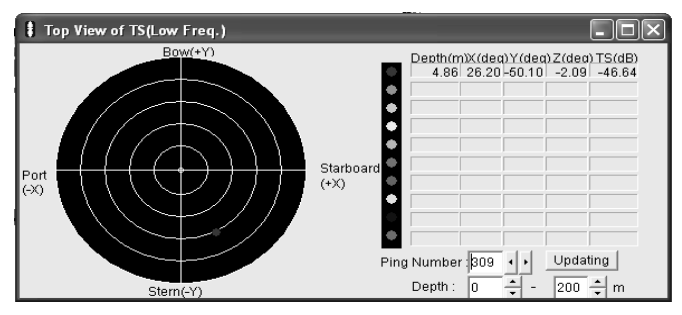

(a) View of single fish detected (one ping)

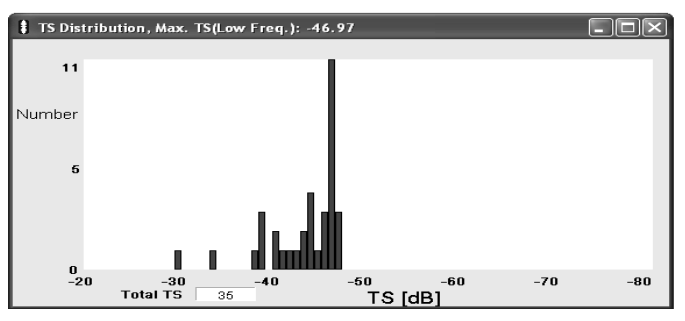

(b) View of TS data (one file)

Figure 6. Echogram view

Depth, position (x-y-z), and TS of fish detected ping-by-ping can be monitored by Top View of TS (a), whereas total of TS data at file-by-file can be shown by Distribution of TS (b).
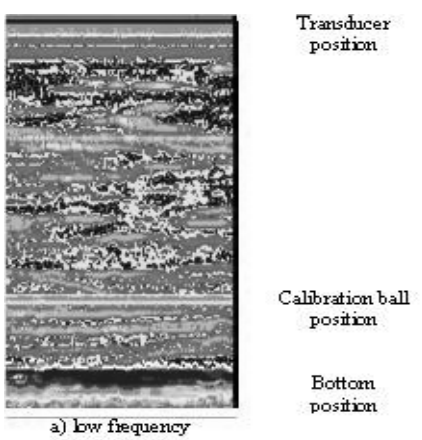

(a) Echogram of calibration ball position
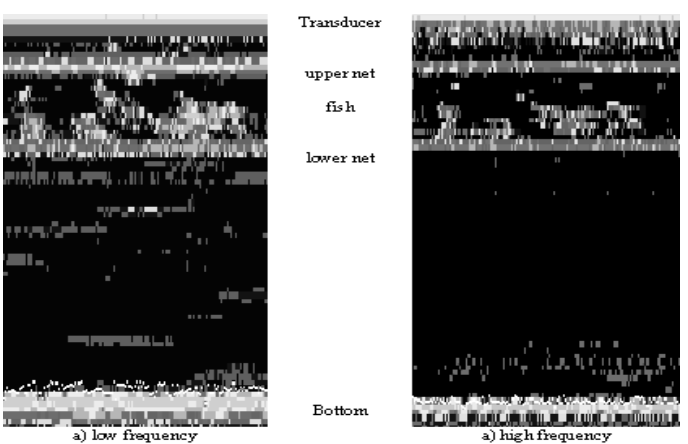

(b) Echogram of fish in the net cage

Figure 7. Recorded echogram.

The position of seabed and calibration ball from transducer (a) and fish abundance in the net cage (b) can be monitored using echogram. 